Aim of the study: To study the effect of thyroid transcription factor-1 (TTF-1) expression on ipsilateral mediastinal nodal (N2) metastases in primary adenocarcinoma of the lung.

Material and methods: The patients operated on with a diagnosis of primary adenocarcinoma of the lung were retrospectively analyzed and divided into two groups according to their TTF-1 expression. The relationship between TTF-1 expression and N2 metastases was evaluated.

Results: There were 73 patients ( 58 male, 15 female) with a mean age of 58.4 \pm 10.2 in the study group. Sixty-six lobectomies or pneumonectomies and mediastinal lymph node dissection, and seven mediastinoscopies were performed. Positivity of the TTF-1 protein expression detected by the immunohistochemical staining of the specimens was present in 33 patients ( $45.2 \%$ ); these patients were classified as group $A$ and the rest of the patients as group B. Eleven patients had $\mathrm{N} 2$ disease in group $\mathrm{A}$ versus five patients in group $B$ and the difference between the two groups was statistically significant. Conclusions: Patients with primary adenocarcinoma of the lung having TTF-1 expression are more likely to have N2 disease. They might be considered as candidates for adjuvant therapy.

Key words: thyroid transcription factor-1, N2, adenocarcinoma, lung.

\section{The effect of TTF-1 expression on ipsilateral mediastinal nodal (N2) metastases in primary adenocarcinoma of the lung}

\author{
Ozgur Samancilar ${ }^{1}$, Seyda Ors Kaya ${ }^{1}$, Kenan Can Ceylan ${ }^{1}$, Ozan Usluer $^{1}$, \\ Ali Galip Yener ${ }^{2}$
}

${ }^{1}$ Department of Thoracic Surgery, Dr. Suat Seren Chest Diseases and Thoracic Surgery Research and Training Hospital, Izmir, Turkey

2Department of Pathology, Dr. Suat Seren Chest Diseases and Thoracic Surgery

Research and Training Hospital, Izmir, Turkey

\section{Introduction}

Lung cancer is the most common cause of cancer death in many countries. Surgical treatment is the optimum treatment method for early stage non-small cell lung cancer (NSCLC). Despite complete resection, 23\% of patients with pathological stage T1aNOMO according to the revised Union for International Cancer Control (UICC)/American Joint Committee on Cancer (AJCC) classification are expected to die within 5 years after intent-to-cure surgery, implying that NSCLC can be micrometastatic even at diagnosis [1]. The benefit of adjuvant treatment for 5-year overall survival does not exceed 5\% [2]. Furthermore, the improvement of overall survival seems to be limited to stages II and III [3,4]. Several studies in the literature have focused on analyzing the possible factors causing local or distant recurrence or factors predicting poor survival in patients having NSCLC to better choose the best candidates for adjuvant chemotherapy [5-13].

Thyroid transcription factor 1 (TTF-1), also known as Nkx2.1 or thyroidspecific enhancer-binding protein, is a $38-k D a$ nuclear protein encoded by a gene located on chromosome 14q13. TTF-1 is expressed in the thyroid, the lung and the diencephalon during embryogenesis. It plays a physiological role in the development and the morphogenesis of the thyroid and the lung during embryogenesis [14]. TTF-1 is more frequently expressed in adenocarcinoma and small cell carcinoma so it is widely used in the differential diagnosis of metastatic and primary lung adenocarcinomas even in frozen section or cytological preparations [15-17]. The role of TTF-1 in the development of lung cancer is not clear. It was suggested that TTF-1 could promote development of cancer by regulating the activity of proliferating cells and the formation of new vessels, at least in adenocarcinoma, and by increasing the rate of proliferation $[18,19]$. In this study, the role of TTF-1 expression in N2 metastases in primary adenocarcinoma of the lung is investigated.

\section{Material and methods}

Patients operated on between January 2009 and December 2010 with the diagnosis of primary adenocarcinoma of the lung were analyzed retrospectively. All the patients were evaluated by chest X-ray, computed tomography (CT) scan of the chest and a whole body positron emission tomography (PET)/CT scan before the operation. Preoperative invasive staging methods such as mediastinoscopy were performed for positive mediastinal lymph nodes on PET/CT scan. Anatomic resection and mediastinal lymph node dissection was performed 
for all patients with no evidence of mediastinal lymph node involvement or distant metastasis.

Formalin-fixed, paraffin-embedded sections were stained with TTF-1 antibodies (clone 8G7G3/1, Neomarkers Co., Fremont, California, USA). Immunohistochemical staining was performed using a streptavidin biotin peroxidase system (DAKO LSAB kit). For TTF-1 staining, slides were treated with $3 \%$ hydrogen peroxide heated in antigen retrieval solution. The slides were allowed to cool at room temperature for 20 minutes and then were rinsed with deionized water. After immersing in aminomethane-buffered saline, pH 7.6, containing a $0.05 \%$ solution of polysorbate 20 for 5 minutes, the slides were transferred to an immunochemical stainer. The slides were stained with primary antibodies. Tumors were designated positive for TTF-1 when their cells displayed distinct brown nuclear staining (Fig. 1). Semi-quantitative scoring of TTF-1 positivity is defined as diffuse (more than 50\% tumor cells are positive for TTF-1) and focal (less than 50\% tumor cells are positive for TTF-1).

The patients were divided into two groups according to their thyroid transcription factor-1 (TTF-1) expression. The relationship between TTF-1 expression and N2 disease was evaluated.

SPSS 15.0 was used for the statistical analysis. Fisher's exact test or Pearson chi square test was performed to compare the variables of the two groups.

\section{Results}

There were 73 patients ( 58 male, 15 female) with a mean age of $58.4 \pm 10.2$ in the study group. The demographics of the patients are summarized in Table 1 and subtypes of adenocarcinoma are presented in Table 2. Sixty-six lobectomies or pneumonectomies and mediastinal lymph node dissection, and seven mediastinoscopies were performed. The mean number of lymph nodes dissected was 13.3.

TTF-1 expression detected by the immunohistochemical staining of the specimens was present in 33 patients (45.2\%); these patients were classified as group A and the rest of the patients as group B. Eleven patients had N2 disease in group A versus five patients in group $B$ and the dif- ference between the two groups was statistically significant $(p=0.046)$.

TTF-1 positivity was found to be diffuse in 18 (54\%) and focal in 15 (46\%) patients after the examination of the histopathological specimens.

\section{Discussion}

Thyroid transcription factor-1 is expressed in lung cancer and generally used in the differential diagnosis of metastatic and lung adenocarcinomas but its functional roles remain unexplored. In the lung, TTF-1 controls the expression of surfactant proteins that are essential for lung stability and lung host defense. Recent studies have implicated TTF-1 as a lineage-specific proto-oncogene for lung cancer [20].

The prognostic value of TTF-1 for NSCLC has also been investigated but different results have been obtained from these studies. Berghmans and colleagues [14] reported their meta-analysis on this topic in 2006 and found that TTF-1 is associated with statistically significant reduced survival in one and improved survival in four studies. They concluded that TTF-1 is a good prognostic factor for survival in NSCLC

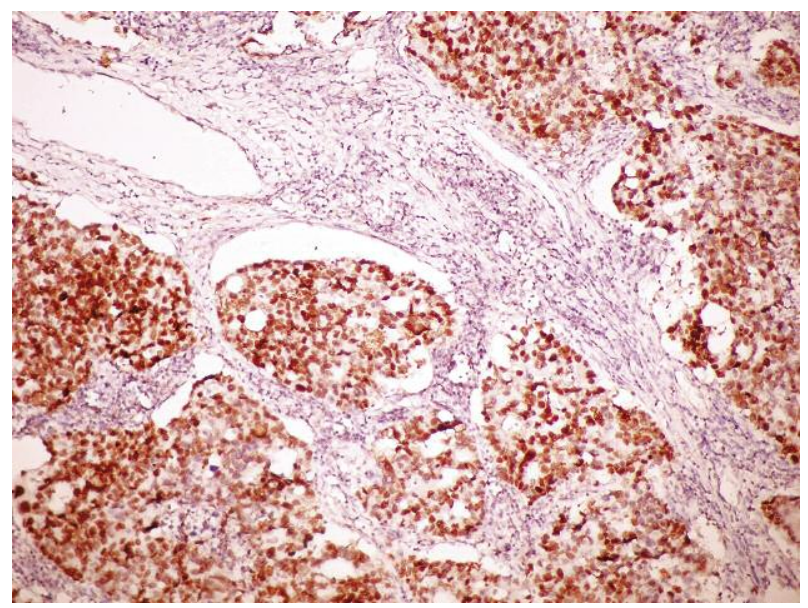

Fig. 1. Diffuse brown nuclear staining in the tumor cells $(10 \times 10)$

Table 1. Patients' characteristics of the two study groups and the results of the statistical analysis

\begin{tabular}{|c|c|c|c|c|}
\hline Variables and subsets & TTF-1 (+) & TTF-1 (-) & Total & $p$ value \\
\hline Patients, $n(\%)$ & $33(45.2 \%)$ & $40(54.8 \%)$ & 73 & \\
\hline Mean age & $57.7 \pm 9.2$ & $59.1 \pm 11.0$ & $58.4 \pm 10.2$ & 0.23 \\
\hline $\begin{array}{l}\text { Gender } \\
\text { male } \\
\text { female }\end{array}$ & $\begin{array}{c}26(44.8 \%) \\
7(46.6 \%)\end{array}$ & $\begin{array}{c}32(55.2 \%) \\
8(53.3 \%)\end{array}$ & $\begin{array}{l}58(79 \%) \\
15(21 \%)\end{array}$ & 1 \\
\hline $\begin{array}{l}\text { Type of operation } \\
\text { mediastinoscopy } \\
\text { lobectomy } \\
\text { pneumonectomy }\end{array}$ & $\begin{array}{c}5 \\
26 \\
2\end{array}$ & $\begin{array}{c}2 \\
36 \\
2\end{array}$ & $\begin{array}{c}7 \\
62 \\
4\end{array}$ & \\
\hline Mean tumor diameter $(\mathrm{cm})$ & $3.7 \pm 1.5$ & $4.1 \pm 2.1$ & $3.9 \pm 1.9$ & 0.35 \\
\hline Mean number of lymph nodes removed & $15.1 \pm 8.0$ & $11.9 \pm 5.1$ & $13.3 \pm 6.6$ & 0.11 \\
\hline N2 (+) lymph nodes & $11(68.7 \%)$ & $5(31.3 \%)$ & $16(21.9 \%)$ & 0.046 \\
\hline
\end{tabular}

TTF-1 - thyroid transcription factor-1 
Table 2. Subtypes of adenocarcinoma in the study population

\begin{tabular}{|lc|}
\hline Subtypes & $n(\%)$ \\
\hline acinar & $21(29)$ \\
\hline papillary & $13(19)$ \\
\hline bronchioloalveolar & $1(1)$ \\
\hline solid adenocarcinoma with mucin & $3(3)$ \\
\hline mixed subtypes & $35(48)$
\end{tabular}

and they also suggested that this effect also appears significant when the analysis is restricted to patients with adenocarcinoma. Martins et al. [21] reported that patients with high TTF-1 and low metalloproteinase-9 (MMP-9) are in the low-risk group while those with low TTF-1 and high metalloproteinase-9 (MMP-9) are in the high-risk group for NSCLC deaths. Saito and colleagues [22] stated that TTF-1 inhibits transforming growth factor-beta-mediated epithelial-tomesenchymal transition in lung adenocarcinoma cells and suggested that modulation of TTF-1 expression can be a novel therapeutic strategy for treatment of lung cancer. Bai $[23,24]$ concluded that both TTF-1 and TTF-1 mRNA expression often indicates high likeliness of lung carcinoma metastasis. Barletta [25] studied the clinical significance of TTF-1 protein expression and TTF-1 gene amplification in lung adenocarcinoma and concluded that TTF- 1 expression is a predictor of good outcome in patients with lung adenocarcinoma. Patients with no TTF-1 expression or TTF-1 expression and TTF-1 gene amplification tend to have a significantly worse prognosis than patients with TTF-1 expression and no TTF-1 gene amplification. Lastly, Yoon [26] reported that TTF-1 mRNA-positive circulating tumor cells in the peripheral blood predict poor prognosis in surgically resected non-small cell lung cancer patients and that monitoring of TTF-1 (+) circulating tumor cells status after surgery may be useful for identifying high-risk patients among surgically resected NSCLC cases. So, according to most of the literature mentioned above, TTF-1 expression seems to be a good prognostic factor for NSCLC patients, especially for patients with adenocarcinoma.

There is only one study in the literature that has investigated the relation between TTF-1 positivity and the occurrence of lymph node metastases in patients with lung cancer, with a limited number of patients [27]. They also found a statistically significant association between TTF-1 positivity and both hilar and mediastinal lymph node metastases.

Even though the results from the literature show that TTF-1 positivity is a good prognostic factor for NSCLC patients, our results suggest that patients with adenocarcinoma having TTF-1 positivity tend to have mediastinal lymph node metastases. We did not evaluate the relationship with TTF-1 positivity and its effect on survival as the mean followup period for our study group is short.

In conclusion, TTF-1 expression may be a predictor of mediastinal lymph node metastases in patients with lung adenocarcinoma and these patients might be candidates for adjuvant therapy.

This study was presented as a poster presentation at the 14th World Conference on Lung Cancer, 2011, Amsterdam.
The authors declare no conflict of interest.

\section{References}

1. Rami-Porta R, Crowley JJ, Goldstraw P. The revised TNM staging for lung cancer. Ann Thorac Cardivasc Surg 2009; 15: 4-9.

2. Arriagada R, Auperin A, Burdett S, et al. Adjuvant chemotherapy, with or without postoperative radiotherapy, in operable nonsmall-cell lung cancer: two meta-analyses of individual patient data. Lancet 2010; 375: 1267-77.

3. Pignon JP, Tribodet H, Scagliotti GV, et al; LACE Collaborative Group. Lung adjuvant cisplatin evaluation: a pooled analysis by the LACE Collaborative Group. J Clin Oncol 2008; 26: 3552-9.

4. Strauss GM, Herndon JE 2nd, Maddaus MA, et al. Adjuvant paclitaxel plus carboplatin compared with observation in stage IB nonsmall-cell lung cancer: CALGB 9633 with the Cancer and Leukemia Group B, Radiation Therapy Oncology Group, and North Central Cancer Treatment Group Study Groups. J Clin Oncol 2008; 26: 5043-51.

5. Turhan K, Samancilar O, Cagirici U, Goksel T, Nart D, Cakan A, Cok G. The effect of blood vessel invasion on prognosis of operated stage I non-small cell lung cancer patients. Thorac Cardiovasc Surg 2010; 58: 28-31.

6. Maeda R, Yoshida J, Ishii G, Hishida T, Nishimura M, Nagai K. Risk factors for tumor recurrence in patients with early-stage (stage and II) non-small cell lung cancer: patient selection criteria for adjuvant chemotherapy according to the seventh edition TNM classification. Chest 2011; 140: 1494-502.

7. Ucvet A, Kul C, Gursoy S, Erbaycu AE, Kaya SO, Dinc ZA, Yucel N. Prognostic value of epithelial growth factor receptor, vascular endothelial growth factor, E-cadherin, and p120 catenin in resected non-small cell lung carcinoma. Arch Bronconeumol 2011; 47: 397-402.

8. Kobayashi N, Toyooka S, Soh J, et al. Risk factors for recurrence and unfavorable prognosis in patients with stage I non-small cell lung cancer and a tumor diameter of 20 mm or less. J Thorac Oncol 2007; 2: 808-12.

9. Meert AP, Martin B, Paesmans M, et al. The role of HER-2/neu expression on the survival of patients with lung cancer: a systematic review of the literature. Br J Cancer 2003; 89: 959-65.

10. Martin B, Paesmans M, Mascaux C, Berghmans T, Lothaire P, Meert AP, Lafitte JJ, Sculier JP. Ki-67 expression and patients survival in lung cancer: systematic review of the literature with meta-analysis. Br J Cancer 2004; 91: 2018-25.

11. Mascaux C, lannino N, Martin B, et al. The role of RAS oncogene in survival of patients with lung cancer: a systematic review of the literature with meta-analysis. Br J Cancer 2005; 92: 131-9.

12. Steels E, Paesmans M, Berghmans T, et al. Role of p53 as a prognostic factor for survival in lung cancer: a systematic review of the literature with a meta-analysis. Eur Respir J 2001; 18: 705-19.

13. Kasprzyk M, Dyszkiewicz W, Roszak M, Gabryel P, Gałęcki B. Are preoperative acute phase proteins serum levels associated with clinical outcome in non-small cell lung cancer patients? Kardiochirur Torakochirur Pol 2010; 7: 415-20.

14. Berghmans T, Paesmans M, Mascaux C, Martin B, Meert AP, Haller A, Lafitte JJ, Sculier JP. Thyroid transcription factor 1 - a new prognostic factor in lung cancer: a meta-analysis. Ann Oncol 2006; 17: $1673-6$.

15. Ordóñez NG. Thyroid transcription factor-1 is a marker of lung and thyroid carcinomas. Adv Anat Pathol 2000; 7: 123-7.

16. Moldvay J, Jackel M, Bogos K, Soltész I, Agócs L, Kovács G, Schaff Z. The role of TTF-1 in differentiating primary and metastatic lung adenocarcinomas. Pathol Oncol Res 2004; 10: 85-8.

17. Hecht J, Pinkus JL, Weinstein LJ, Pinkus GS. The value of thyroid transcription factor- 1 in cytologic preparations as a marker for metastatic adenocarcinoma of lung origin. Am J Clin Pathol 2001; 116: 483-88.

18. Pelosi G, Fraggetta F, Pasini F, et al. Immunoreactivity for thyroid transcription factor-1 in stage I non-small cell carcinomas of the lung. Am J Surg Pathol 2001; 25: 363-72. 
19. Puglisi F, Barbone F, Damante G, Bruckbauer M, Di Lauro V, Beltrami CA, Di Loreto C. Prognostic value of thyroid transcription factor-1 in primary, resected, non-small cell lung carcinoma. Mod Pathol 1999; 12: 318-24.

20. Boggaram V. Thyroid transcription factor-1 (TTF-1/Nkx2.1/TITF1) gene regulation in the lung. Clin Sci (Lond) 2009; 116: 27-35.

21. Martins SJ, Takagaki TY, Silva AG, Gallo CP, Silva FB, Capelozzi VL Prognostic relevance of TTF- 1 and MMP-9 expression in advanced lung adenocarcinoma. Lung Cancer 2009; 64: 105-9.

22. Saito RA, Watabe T, Horiguchi K, Kohyama T, Saitoh M, Nagase T, Miyazono K. Thyroid transcription factor-1 inhibits transforming growth factor-beta-mediated epithelial-to-mesenchymal transition in lung adenocarcinoma cells. Cancer Res 2009; 69: 2783-91.

23. Bai XY, Shen H. Quantitative study of thyroid transcription factor-1 protein expression in lung carcinoma cell nucleus by tissue microarray. Nan Fang Yi Ke Da Xue Xue Bao 2006; 26: 1423-6.

24. Bai XY, Shen H. Quantitative analysis of thyroid transcription factor-1 mRNA expressions in primary lung cancer and its metastatic foci. Nan Fang Yi Ke Da Xue Xue Bao 2008; 28: 20-5.

25. Barletta JA, Perner S, lafrate AJ, et al. Clinical significance of TTF-1 protein expression and TTF-1 gene amplification in lung adenocarcinoma. J Cell Mol Med 2009; 13: 1977-86.

26. Yoon SO, Kim YT, Jung KC, Jeon YK, Kim BH, Kim CW. TTF-1 mRNApositive circulating tumor cells in the peripheral blood predict poor prognosis in surgically resected non-small cell lung cancer patients. Lung Cancer 2011; 71: 209-16.

27. Altaner S, Yoruk Y, Tokatli F, Koçak Z, Tosun B, Guresci S, Kutlu K. The correlation between TTF-1 immunoreactivity and the occurrence of lymph node metastases in patients with lung cancer. Tumori 2006; 92: 323-6.

\section{Address for correspondence}

\section{Ozgur Samancilar}

Dr. Suat Seren Gogus Hastanesi

Gogus Cerrahisi Klinigi, K Blok

Yenisehir, Izmir Turkey

fax +902324587262

e-mail: ozgursamancilar@hotmail.com

Submitted: $\quad 6.06 .2012$

Accepted: $\quad 7.08 .2012$ 